\title{
Üniversite öğrencilerinin yeme davranışlarının Hollanda Yeme Davranışı Anketi (DEBQ) ile değerlendirilmesi: Osmaniye Korkut Ata Üniversitesi Örneği
}

\section{Evaluation of the eating behavior of university students with the Dutch Eating Behavior Questionnaire (DEBQ): The case of Osmaniye Korkut Ata University}

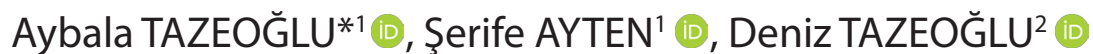

'Osmaniye Korkut Ata Üniversitesi, Sağlık Bilimleri Fakültesi, Beslenme ve Diyetetik Ana Bilim Dalı, OSMANIYE / TÜRKIYE

${ }^{2}$ Mersin Üniversitesi, Genel Cerrahi Anabilim Dalı, Cerrahi Onkoloji Bilim Dalı, MERSiN / TÜRKiYE

\section{Öz}

Amaç: Üniversite döneminde gençlerin ciddi beslenme sorunları yaşadığı bilinmektedir. Bu çalışmada, üniversite öğrencilerinin cinsiyetlerine, yaşadıkları yerlere, vücut kütle indekslerine ve eğitim alanlarına göre yeme davranışlarının incelenmesi hedeflenmiştir.

Gereç ve Yöntemler: Çalışma, Aralık 2019 - Şubat 2020 tarihleri arasında, Osmaniye Korkut Ata Üniversitesi'nde öğrenim gören 726 öğrenci ile yapılmıştır. Yeme davranışları, Türkiye'de yaşayan insanlar üzerinde geçerliliği ve güvenilirliği 2009 yılında Bozan tarafından uyarlanan ve 33 maddeden oluşan Hollanda yeme davranış anketiyle (DEBQ) değerlendirilmiştir. Bu anket duygusal yeme davranışlarını, dışsal yeme davranışlarını ve kısıtlı yeme davranışlarını değerlendiren 3 alt ölçekten oluşmaktadır. Anketteki her bir madde 5'li Likert skalası (1:hiçbir zaman, 2:nadiren, 3:bazen, 4:sık, 5:çok sık) ile değerlendirilmektedir.

Bulgular: Katılımcıların 387 (\%53,3)'si kadın, 339 (\%46,7)'ü erkek olup; yaş ortalaması 22 2 (18-30)'dir. Vücut kitle indeksine (VKi) göre katılımcıların dağıımı incelendiğinde; 66 (\%9) zayıf, 371 (\%51) normal, 241(\%33) fazla kilolu, 51 (\%7) ise obezdir. Cinsiyete göre değerlendirildiğinde, duyusal yemenin kadınlarda fazla olduğu bulundu ( $p<0,01)$. Kısıtlayıcı ve dışlayıcı yemede gruplar arasında anlamlı fark gözlenmedi $(p>0,05)$. Eğitim alanlarına göre; kısıtlayıcı yeme açısından gruplar arasında anlamlı fark saptanmazken $(p=0,18)$; duyusal ve dışlayıcı yeme açısından anlamlı farklılık saptandı ( $p<0,05$, $p=0,02)$. Yaşadıkları yere göre; duyusal, kısıtlayıcı ve dışşal yeme açısından anlamlı farklılık saptandı $(p<0,001, p=0,03$, $p=0,04)$. VKi' ye göre; gruplar arasında duyusal yeme açısından anlamlı fark saptanmazken $(p=0,74)$; dışsal ve kısıtlayıcı yeme davranışı açısından anlamlı farklılık saptandı $(p<0,001, p<0,001)$.

Sonuç: Çalışmamızda, DEBQ'nun alt ölçeklerini kullanarak, öğrencilerin okudukları alanlara, yaşadıkları yere, VKi'lerine, cinsiyetlerine göre oluşan verileri analiz ettik, yeme bozukluğu riski yüksek olan popülasyonun VKi, cinsiyet, okudukları alan ve yaşadıkları çevrenin ilişkili olduğunu gösterdik.

Anahtar kelimeler: yeme bozuklukları; DEBQ; genç; beslenme

Sorumlu yazar*: Aybala Tazeoğlu, Osmaniye Korkut Ata Üniversitesi, Sağlık Bilimleri Fakültesi, Beslenme ve Diyetetik Ana Bilim Dalı, OSMANiYE / TÜRKiYE E-posta: aybala_86@hotmail.com, aybalatazeoglu@korkutata.edu.tr 


\section{Abstract}

Aim: $\mathrm{t}$ is known that young people experience serious nutritional problems during university period. In this study, it was aimed to examine the eating behaviors of university students according to their gender, their place of residence, body mass index and education area.

Material and Methods: The study was carried out with 726 students studying at Osmaniye Korkut Ata University between December 2019 - February 2020. Eating behavior, validity and reliability of the people living in Turkey and the Netherlands in 2009. Impairments adopted by the eating behavior questionnaire consisting of 33 items (DEBQ) were evaluated. This questionnaire consists of 3 subscales that evaluate emotional eating behaviors, external eating behaviors and limited eating behaviors. Each item in the questionnaire is evaluated with a 5-point Likert scale (1: never, 2: rarely, 3: sometimes, 4: frequent, 5: very often).

Results: 387 (53.3\%) of the participants were women and 339 (46.7\%) were men; average age is $22 \pm 2$ (18-30). When the distribution of participants according to body mass index (BMI) is examined; 66 (9\%) are weak, 371 (51\%) are normal, 241 (33\%) are overweight and $51(7 \%)$ are obese. When evaluated by gender, sensory eating was found to be more in women $(p<0.01)$. No significant difference was observed between the groups in restrictive and exclusive food $(p>0.05)$. According to the fields of education; no significant difference was found between the groups in terms of restrictive eating $(p=0.18)$; There was a significant difference in sensory and exclusive eating $(p<0.05, p=0.02)$. According to where they live; There was a significant difference in sensory, restrictive and exogenous eating ( $<<0.001, p=0.03, p=0.04)$. According to the $\mathrm{BMI}$; There was no significant difference in sensory eating between groups $(p=0.74)$; There was a significant difference in terms of external and restrictive eating behavior $(p<0.001, p<0.001)$.

Conclusion: In our study, using the sub-scales of $D E B Q$, we analyzed the data formed according to the areas where students read, where they live, their BMI, gender, and we showed that the population with a high risk of eating disorder is related to the $\mathrm{BMI}$, gender, the area they study and the environment they live in.

Keywords: eating disorders; DEBQ; young; nutrition

\section{Giriş}

Dünya SağlıkÖrgütü (DSÖ) sağlığı; sadece hastalık ve sakatlığın olmayışı değil, insanın fiziksel, zihinsel ve sosyal yönden tam bir iyilik halinde olması şeklinde tanımlamıştır [1]. Fetüsün oluşması ile başlayan beslenme; büyüme ve gelişmenin sağlanması, sağlığın korunması, sürdürülmesi, geliştirilmesi ve yaşam kalitesinin yükseltilmesi için vücudun ihtiyacı olan besin öğelerini yeterli miktarlarda ve uygun zamanlarda almak amacıyla, bilinçli yapılması gereken bir eylemdir [2].

Üniversite öğrencilerinin çoğunluğu aile ortamından uzaklaştıkları için üniversite ortamında hiç tecrübe etmediği yeni alışkanlıklar kazanabilirler. Yaşadıkları coğrafyanın değişmesi, ailelerinden ayrı bir evde - yurtta veya apartta yaşamaya başlamaları, yemek hazırlama alışkanlı̆̆ı edinememeleri, ev yemeği tüketimini azaltmaları, dışarıda yemek yemelerinin daha cazip ve kolay gelmesi gibi dış etkiler ve özgürce karar verebilmeleri sayesinde beslenme alışkanlıkları değişebilmektedir [3]. Bu nedenle üniversite öğrencilerinin çoğunluğu mevcut alışkanlıklarından uzaklaşmakta ve bu yeni ortamda hiç tecrübe etmedikleri beslenme alışkanlıkları ile yetersiz ve dengesiz beslenmeye başlayabilmektedirler [4].
Gençlik dönemi, özellikle 18-24 yaş arası dönem, mevcut sağlığın korunması, geliştirilmesi ve hastalıkların önlenmesi açısından önemli bir yaş dönemi olarak bilinmektedir. Bu nedenle bu yaş döneminde yer alan üniversite öğrencileri, son yıllarda pek çok çalışmanın hedef grubunu oluşturmaktadır [5].

Üniversiteyi yeni kazanmış gençler yaş dönemi olarak incelendiğinde, bu gençlerin ergenliğin son safhalarında oldukları bilinmektedir. Ergenlerde kontrolsüz aşırı yemenin giderek yayıldığı görülmektedir. Obez ergenlerde anksiyete ve depresyon ile kontrol kaybı arasında anlamlı ilişki bulunmuştur. Duygusal yemenin erken tespiti, kilo kontrolünün sağlanması, çarpık yeme bozukluklarııı önlenmesi ve tedavisi için önemlidir [6]. Yapılan bir çalışmada genel ebeveynlik ile duygusal yeme arasındaki ilişki incelenmiş, ebeveynlik ve aile etkileşiminin duygusal yeme üzerinde önemli etkiye sahip olabileceği bildirilmiştir. Ailelerinden ayrı yaşamaya başlayan üniversite öğrencilerinde bu durumun görülebileceği unutulmamalıdır [7]. Topham ve arkadaşları Hollandalı ergenlerin eğitiminde, düşük anne desteğinin, yüksek psikolojik kontrolün ve yüksek davranışsal kontrolün artan duygusal yeme ile ilişkili olduğunu belirtmiş̧ir [8]. 
Ülkemizde gençlerin beslenme alışkanlıkları ile ilgili yapılan araştırmalarda üniversite dönemindeki beslenmede çok ciddi sorunların yaşandığı bildirilmektedir. Öğrencilerin bu dönemde genellikle öğünlerine dikkat etmedikleri, tek öğün yemek yedikleri, sandviç ve simit gibi yiyecekleri daha çok tükettikleri, ekonomik zorlukların yetersiz ve dengesiz beslenme probleminde etkili olduğu, yurtta kalan öğrencilerin yurt şartlarının kötü olmasından dolayı beslenmelerinin iyi olmadığı, sadece karınlarını doyurdukları farklı zamanlarda yapılan araştırmalarda ortaya konulmuştur [9]. Yapılan bir başka çalışmada ise yetersiz ve dengesiz beslenmenin mental gelişme üzerinde de olumsuz etkiler yaptığı, kişilerin zekâ düzeylerinde düşüşe, öğrenmede güçlüğe, davranış bozukluklarına ve neden olduğu belirtilmektedir [10].

Ayrıca duygusal yeme, bulimia ner $\neg$ vozada yeme ataklarını tetikleyen muhtemel bir faktör olarak tanımlanmıştır. Buna göre Bulimia nervozada tıkınırcasına yeme ataklarıy $\neg$ la var olan stres ve negatif duygu durumunun azaltılacağı görüşü mevcuttur. Aneroksiya nervozadaki duygu durumu ise daha çok kişinin yeme davra $\neg$ nışı üzerindeki kontrol mekanizmasını kaybetme korkusu taᄀşıması ile ilişkilendirilmektedir. Her iki durumda da bireyler, içinde bulundukları duygu durumunu tanım-layamadıkları için duygularla baş edebilmenin bir yolu olarak aşırı yeme ya da yememe davranışı sergilemektedirler [11].

Yemek yeme özellikle genç insanlar için otomatik bir süreç değildir. Her birimizin hissettiği kültürel, sosyal ve psikolojik baskılardan büyük oranda etkilenmektedir. Son 30 yılda, yemek yeme motivasyonunu, yeterli besin alımını ve vücut ağırlığı kontrolünü bozabilecek davranışları değerlendirmek için teoriler geliştirilmiştir. Psikolojik teorilere dayanarak, Van Strien ve ark. üç farklı yeme davranışı tanımladı. "Duygusal yeme", içsel fizyolojik açlık sinyalleri olmadan, tokluk sinyalini göz ardı ederek stresi hafifletmek için olumsuz duygularla baş edebilmek için yemeyi ifade eder. "Dışsal yeme”, açlık ve tokluk sinyallerine bakılmaksızın besin tüketimi ile ilgili uyaranlara (besinle karşılaşma veya kokusu) yanıt olarak yeme anlamına gelir. "Kısıtlayıcı yeme" teorisi bilinçli olarak besin alımını kısıtlama derecesini (belirli bir kilo vermek veya korumak için yemekten kaçınma girişimleri) yansıtır [12].

Çoğu çalışma bu üçyeme davranışının beden kitle indeksi (BMI) ile bağlantılı olduğunu göstermiştir [13,14]. Bu üç tür yeme davranışı, Hollanda Yeme Yeme Davranışı Anketi (DEBQ) kullanılarak güvenilir ve geçerli bir şekilde ölçülebilir. DEBQ her birinde $5^{\prime \prime l i}$ Likert ölçeği ("asla" ile "çok sık" arasında değişen) bulunan 33 maddeden oluşmaktadır . Orijinal DEBQ'nun İngilizce versiyonu birçok dile çevrilmiştir: Tüm sürümler iyi faktöriyel geçerlilik göstermiştir. DEBQ, cinsiyetler, ağılık kategorileri ve rastgele numuneler arasında stabil bir faktör yapısına sahiptir [15].

Bu çalışmada, üniversite öğrencilerinin cinsiyet, yaşadıkları yer, beden kütle indeksi ve eğitim gördükleri bölümlere göre yeme davranışlarının incelenmesi hedeflenmiştir.

\section{Materytal ve Metod}

Çalışmamız; Aralık 2019 - Şubat 2020 tarihleri arasında, Osmaniye Korkut Ata Üniversitesi'nde eğitim ve öğrenim görmekte olan 726 öğrencinin katılımı ile yapılmıştır. Katılımcılar çalışmaya gönüllü olarak katılmışlardır.

Çalışmaya üniversitemiz öğrencisi olan ve herhangi bir kronik hastalık öyküsü olmayan öğrenciler gönüllülük esasına göre dahil edilmiştir. Kronik hastalığı olmak ve üniversitemiz öğrencisi olmamak dışında çalışma harici tutulma kriteri bulunmamaktadır.

Katılımcıların demografik verileri (yaş, cinsiyet), vücut ağırııları, boy uzunluğu, eğitim gördükleri fakülte, eğitim süresince konaklama bilgisi sordu ve ardından yeme davranışlarını değerlendirmek amacıyla anket uygulandı.

Araştırmaya katılan bireylerin yeme davranışlarının değerlendirilmesinde Türkçe geçerlilik ve güvenilirliği 2009 yılında Bozan tarafından yapılan [13], 33 maddeden oluşan Hollanda yeme davranış anketi (DEBQ) kullanılmıştır. Bu anket duygusal yeme davranışlarını, dışsal yeme davranışlarını ve kısıtlı yeme davranışlarını değerlendiren 3 alt ölçekten oluşmaktadır. Ankette yer alan maddeler 5 'li Likert skalası ile değerlendirilmektedir (1: hiçbir zaman, 2: nadiren, 3: bazen, 4: sık, 5: çok sık). Testin toplam skoru değerlendirilmemekte 3 alt ölçek kendi içinde değerlendirilmektedir. Testin skorlamasında her hangi bir kesim noktası olmazken 3 alt ölçeğin kendi içinde değerlendirilen toplam puanının yüksek olması yeme davranışı ile ilgili olumsuzluğu göstermektedir. Hollanda Yeme Davranışı anketinin Türkçe versiyonunda ilk 10 soru kısıtlı yeme, 11-23 arası duygusal yeme, 24-33 arası ise dışsal yeme tutumunu değerlendiren sorulardır. Dışsal yeme skalasında bulunan 31. soru ise ters sorudur. Verilerin istatistiksel analizinde SPSS (IBM SPSS Statistics 21) paket programı kullanılmıştır. Bulguların yorumlanmasında tanımlayıcı istatistikler kullanılmıştır. Tanımlayıcı değerler sayı $(n)$, yüzde (\%), aritmetik ortalama $(\mathbb{Q} \mathbb{X})$, standart sapma (SS), medyan (M) ve çeyrekler arası (IQR) olarak belirtilmiştir. Parametrik yöntemlere uygun şekilde, iki bağımsız değişkenin karşılaştırılmasında "Indepedent Sample-t" test (t-tablo değeri), ikiden fazla bağımsız değişkenin karşılaştııılmasında One-way ANOVA testi kullanılmıştır. İki nitel değişkenin 
birbiriyle olan ilişkilerinin incelenmesinde beklenen değer düzeylerine göre X2-çapraz tabloları kullanılmıştır.

\section{Bulgular}

Çalışmamıza katılan öğrencilerin $387(\% 53,3)^{\prime}$ 'si kadın, 339 (\%46,7)'ü erkek olup; yaş ortalaması $22 \pm 2$ (min:18,max:30) idi. Vücut kitle indeksi (VKi) ortanca değeri 23,9 (IQR: 20,9-26,6). Katılımcıların VKI'ne göre dağlımı incelendiğinde; 66 (\%9) zayıf, 371 (\%51) normal, 241 (\%33) fazla kilolu, 51 (\%) ise obez idi (Tablo 1).

Katılımcıların eğitim gördükleri bölümlere göre dağılımı incelendiğinde; $118^{\prime i}(\% 16,3)$ sağlık bilimleri, 169'u $(\% 23,3)$ mühendislik, 98'i $(\% 13,5)$ fen-edebiyat, 68'i $(\% 9,4)$ ilahiyat, 167 'si (\%23) iktisadi ve idari bilimler fakültesi (iiBF) ve 106'si $(\% 14,6)$ meslek yüksek okulu (MYO) idi (Tablo 1).

Katılımcıların konaklama yeri incelendiğinde; 80 (\%11)'ı ailesiyle evde, 143'ü $(\% 19,7)$ arkadaşlarıyla evde, $56(\% 7,7)$ 'sı ailesi ve ev arkadaşı olmadan evde, 368 (\%55)'i devlet yurdunda ve 84 'ü (\%12) ise özel yurtta kalıyordu. Katılımcıların büyük çoğunluğu (\%89) Osmaniye dışından gelmişti ( Tablo 1).

\begin{tabular}{|c|c|c|}
\hline & & $\%$ \\
\hline \multicolumn{3}{|l|}{ Cinsiyet } \\
\hline Kadın & 387 & 53,3 \\
\hline Erkek & 339 & 46,7 \\
\hline \multicolumn{3}{|l|}{ VKi } \\
\hline Zayıf & 63 & 8,7 \\
\hline Normal & 371 & 51,1 \\
\hline Fazla kilolu & 241 & 33,2 \\
\hline Obez & 51 & 7,0 \\
\hline \multicolumn{3}{|c|}{ Eğitim alınan alan } \\
\hline Sağlık & 118 & 16,3 \\
\hline Mühendislik & 169 & 23,3 \\
\hline Fen-edebiyat & 98 & 13,5 \\
\hline İlahiyat & 68 & 9,4 \\
\hline $\mathrm{IiBF}$ & 167 & 23 \\
\hline MYO & 54 & 15,8 \\
\hline \multicolumn{3}{|c|}{ Yaşadığı yere göre } \\
\hline Ailesi ile & 75 & 10,3 \\
\hline Arkadaşları ile & 143 & 19,7 \\
\hline KYK & 368 & 50,7 \\
\hline Özel yurt & 84 & 11,6 \\
\hline Evde tek & 56 & 7,7 \\
\hline
\end{tabular}

Cinsiyete göre değerlendirildiğinde, duygusal yeme davranışının kadınlarda erkeklere göre istatistiksel olarak anlamlı farklılık yaratacak düzeyde fazla olduğu tespit edilmişken; kıııtlayııı ve dışlayıcı yeme davranışında gruplar arasında anlamlı fark gözlenmedi (Tablo 2).

\begin{tabular}{|c|c|c|c|}
\hline & Kısıtlayıcı Yeme & Duygusal Yeme & Dışlayıcı Yeme \\
\hline Kadın & $2,26 \pm 0,75$ & $2,49 \pm 0,99$ & $3,14 \pm 0,66$ \\
\hline Erkek & $2,29 \pm 0,78$ & $2,06 \pm 0,99$ & $3,10 \pm 0,74$ \\
\hline $\mathrm{p}$ & 0,52 & 0,001 & 0,51 \\
\hline
\end{tabular}

Katılımcılar eğitim gördükleri bölümlere göre yeme davranışları değerlendirildiğinde; kısıtlayıcı yeme davranışı açısından anlamlı fark saptanmazken (ANOVA, $p=0,18$ ); duygusal ve dışlayıcı yeme davranışı açısından anlamlı farklılık saptandı (ANOVA, $p<0,05, \mathrm{p}=0,02$ ) (Tablo 3).

Mühendislik fakültesi öğrencilerinde, fen-edebiyat $(p<0,05)$ ve IilBF öğrencilerine $(p=0,03)$ göre daha az duygusal yeme davranışı tespit edildi [ANOVA-Tukey (Post-Hoc)] (Tablo 3).

Mühendislik fakültesi öğrencilerinde fen edebiyat fakültesi öğrencilerine göre daha fazla dışlayıcı yeme davranışı tespit edildi [ANOVA-Games Howel (Post-Hoc)] (Tablo 3).

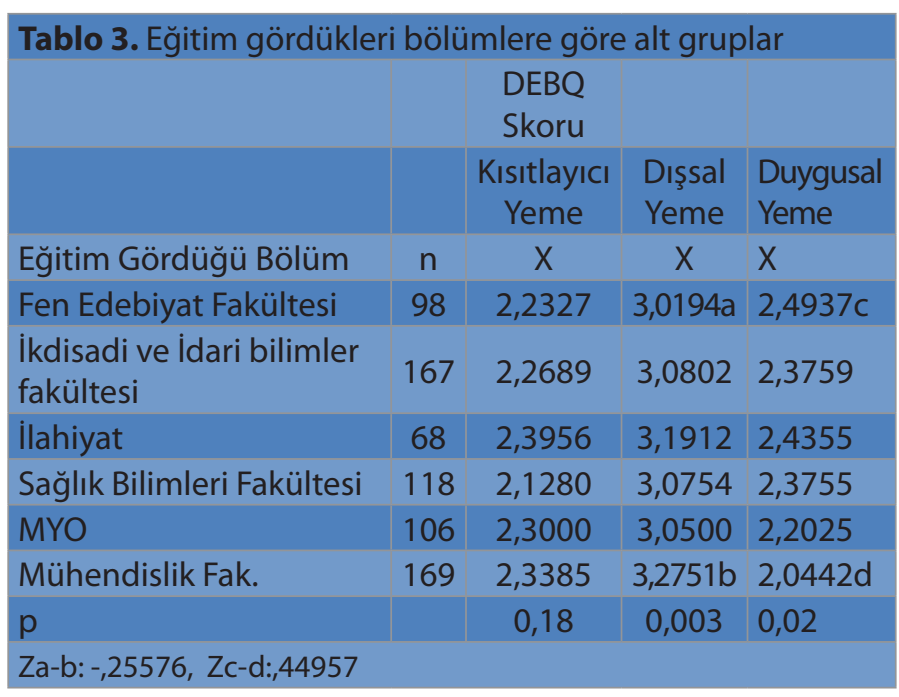

Katılımcıların beden kitle indekslerine göre yeme davranışları değerlendirildiğinde; duygusal yeme davranışı açısından anlamlı fark saptanmazken (ANOVA, $p=0,74$ ); dışsal ve kısıtlayıcı yeme davranışı açısından anlamlı farkıııı saptandı (ANOVA, $p<0,001, p<0,001$ ) (Tablo 4).

Obez grupta dışsal yeme skoru, zayıf, normal ve fazla kilolu gruplarından daha düşük bulunmuştur. Diğer gruplar arasında farklılıklar anlamlı değildir (Tablo 4).

Kısıtlayıcı yeme skoru, zayıf grupta diğer üç gruba göre daha düşük bulunurken, fazla kilolu grupta normal ve obez gruba göre yeme bozukluğu daha yüksek bulunmuştur. Diğer gruplar arasında anlamlı farklılık yoktur [ANOVA-Games Howel (Post-Hoc)] (Tablo 4). 


\begin{tabular}{|c|c|c|c|c|}
\hline \multicolumn{5}{|l|}{ DEBQ Skoru } \\
\hline & & $\begin{array}{l}\text { Dışsal } \\
\text { Yeme }\end{array}$ & $\begin{array}{l}\text { Kısıtlayıcı } \\
\text { Yeme }\end{array}$ & $\begin{array}{l}\text { Duygusal } \\
\text { Yeme }\end{array}$ \\
\hline VKI & $n$ & $X$ & $x$ & $x$ \\
\hline Zayıf & 63 & $3,3143 a$ & 1,5667e & 2,1941 \\
\hline Normal & 371 & $3,1671 b$ & $2,2615 f$ & 2,3212 \\
\hline Fazla kilolu & 241 & $3,0722 c$ & $2,4979 \mathrm{~g}$ & 2,2672 \\
\hline Obez & 51 & $2,8000 d$ & $2,1765 h$ & 2,3575 \\
\hline$p$ & & 0,001 & 0,001 & 0,74 \\
\hline $\begin{array}{l}\text { Za-d: ,51429, } \\
\text { Z:e-f:-,69479, }\end{array}$ & $\begin{array}{l}5712 \\
312\end{array}$ & $\begin{array}{l}\text { d:,27220 } \\
\text {-h:-,60980 }\end{array}$ & & \\
\hline
\end{tabular}

Katılımcılarkadın ve erkekgrubu olarakbeden kitle indekslerine göre yeme davranışları açısından değerlendirildiğinde; her iki grupta da alt grupların yeme skorları (kısıtlayıcı, dışsal ve duygusal yeme davranışları) açısından anlamlı fark vardır (ANOVA, p<0,05) (Tablo 5).

Fazla kilolu grubunda kadınların duygusal yeme skoru, zayıf, normal ve obez gruplarından daha yüksek bulunmuştur. Zayıf grupta Dışsal yeme skoru, normal, fazla kilolu ve obez gruplarından daha yüksek bulunurken, normal grupta obez grubuna göre daha yüksek bulunmuştur. Diğer gruplar arasındaki farklılıklar anlamlı değildir (Tablo 5).

Kısıtlayıcı yeme skoru, zayıf grupta diğer üç gruba göre daha düşük bulunurken, fazla kilolu grupta normal ve obez gruba göre daha yüksek bulunmuştur. Diğer gruplar arasında anlamlı farklılık yoktur [ANOVA-Games Howel (Post-Hoc), p>0,05] (Tablo 5).

\begin{tabular}{|c|c|c|c|c|}
\hline \multicolumn{5}{|c|}{$\begin{array}{l}\text { Tablo 5: Kadınlarda beden kitle indel } \\
\text { DEBQ Skoru }\end{array}$} \\
\hline Kadın & & $\begin{array}{l}\text { Dişsal } \\
\text { Yeme }\end{array}$ & $\begin{array}{l}\text { Kısıtlayıcı } \\
\text { Yeme }\end{array}$ & $\begin{array}{l}\text { Duygusal } \\
\text { Yeme }\end{array}$ \\
\hline VKi & $n$ & $x$ & $X$ & $x$ \\
\hline Zayıf & 53 & $3,4132 a$ & $1,5434 \mathrm{e}$ & 2,2337 \\
\hline Normal & 251 & $3,1546 b$ & $2,3163 f$ & $2,4214 j$ \\
\hline Fazla Kilolu & 60 & $2,9550 c$ & $2,6900 \mathrm{~g}$ & $3,1654 \mathrm{k}$ \\
\hline Obez & 21 & $2,8000 d$ & $2,1286 \mathrm{~h}$ & $2,1099 m$ \\
\hline$p$ & & 0,001 & 0,001 & 0,001 \\
\hline \multicolumn{5}{|c|}{$\begin{array}{l}\text { Z a-b:,25869, Z a-c: ,45821, Za-d:,61321, Zb-d:,35458 } \\
\text { Z:e-f:-,77294, Ze-g:-1,114660, Ze-h:-,58518, Z f-g:-,37367, Zg-h:,56143 } \\
\text { Z:k-l:,93171, Zk-j:,74399, Zk-m:,1,05549 }\end{array}$} \\
\hline
\end{tabular}

Erkeklerde duygusal yeme skoru, obez grubunda fazla kilolu grubuna göre daha yüksek bulunmuştur. [ANOVA-Tukey (PostHoc)] (Tablo 6).

Obez grupta dışsal yeme skoru, normal ve fazla kilolu gruplarından daha düşük bulunmuştur. Diğer gruplar arasındaki farklılıklar anlamlı değildir (Tablo 6).
Kısıtlayıcı yeme skoru, zayıf grupta diğer üç gruba göre daha düşük bulunmuştur. Diğer gruplar arasında anlamlı farklılık yoktur [ANOVA-Games Howel (Post-Hoc)] (Tablo 6).

\begin{tabular}{|c|c|c|c|c|}
\hline \multicolumn{5}{|c|}{ DEBQ Skoru } \\
\hline Erkek & & Dışsal Yeme & Kısıtlayıcı Yeme & Duygusal Yeme \\
\hline VKi & $\mathrm{n}$ & $x$ & $x$ & $x$ \\
\hline Zayıf & 10 & 2,7900 & $1,6900 d$ & 1,9846 \\
\hline Normal & 120 & $3,1933 a$ & $2,1467 e$ & 2,1115 \\
\hline Fazla Kilolu & 181 & $3,1110 b$ & $2,4343 f$ & $1,9694 \mathrm{~h}$ \\
\hline Obez & 30 & $2,8000 c$ & $2,2100 \mathrm{~g}$ & $2,5308 \mathrm{I}$ \\
\hline$p$ & & 0,01 & 0,032 & 0,034 \\
\hline \multicolumn{5}{|c|}{$\begin{array}{l}\text { Z a-c: ,39333, Za-c:,31105 } \\
\text { Z:d-e:-,45667, Zd-f:-,74425, Zd-g:-,52000 } \\
\text { Z:k-ı:,93171, Zk-j:,74399, Zk-m:,1,05549 }\end{array}$} \\
\hline
\end{tabular}

Katılımcılar yaşadıkları yere göre yeme davranışları açısından değerlendirildiğinde; duygusal, kısıtlayıcı ve dışsal yeme davranışları açısından anlamlı farklılıklar saptandı (ANOVA, $p<0,001, p=0,03, p=0,04$ ) (Tablo 7).

Aileden ayrı evde tek yaşayanlarda kısıtlayıcı yeme skoru, devlet yurdunda, özel yurtta ve arkadaşları ile yaşayanlara göre daha düşük bulundu ( $p=0,03, p<0,001, p=0,27)$.Diğer gruplar arasında anlamlı farklılık yoktur [ANOVA-Games Howel (Post-Hoc)] (Tablo 7).

Dışsal yeme skoru, aile ile yaşayanlarda arkadaşlar ile yaşayanlara göre daha düşük bulundu $(p=0,03)$. Diğer gruplar arasında anlamlı farklılık yoktur [ANOVA-Tukey (Post-Hoc)] (Tablo 7).

Duygusal yeme skoru, özel yurtta yaşayanlarda, arkadaşlarıyla yaşayanlardan ve devlet yurdunda yaşayanlardan daha yüksek bulundu $(p<0,001, p=0,02)$. Diğer gruplar arasında anlamlı farklılık yoktur [ANOVA-Games Howel (Post-Hoc)] (Tablo 7).

\begin{tabular}{|c|c|c|c|c|}
\hline \multicolumn{5}{|c|}{ DEBQ Skoru } \\
\hline & & $\begin{array}{l}\text { Kısıtlayıcı } \\
\text { Yeme }\end{array}$ & $\begin{array}{l}\text { Dışsal } \\
\text { Yeme }\end{array}$ & $\begin{array}{c}\text { Duygusal } \\
\text { Yeme }\end{array}$ \\
\hline Yaşadığı yere göre & $\mathrm{n}$ & $\mathrm{X}$ & $\mathrm{X}$ & $\mathrm{X}$ \\
\hline Aile & 75 & 2,1573 & $2,9187 \mathrm{e}$ & 2,3600 \\
\hline Arkadaş ile & 143 & $2,2671 a$ & $3,2790 f$ & $2,1065 \mathrm{~g}$ \\
\hline KYK (DevletYurdu) & 368 & $2,3038 b$ & 3,1054 & $2,2333 \mathrm{~h}$ \\
\hline Özel Yurt & 84 & $2,4607 c$ & 3,0679 & $2,7143 j$ \\
\hline Aileden ayrı evde tek & 56 & $1,9679 d$ & 3,1911 & 2,4629 \\
\hline$p$ & & 0,04 & 0,03 & 0,001 \\
\hline \multicolumn{5}{|c|}{$\begin{array}{l}\text { Za-b: ,29928, Zb-d: ,33595, Zc-d:,49286 } \\
\text { Z:e-f:-,36035 } \\
\text { Zg-j:-,60778, Zh-j:-,48101 }\end{array}$} \\
\hline
\end{tabular}

\section{Tartışma}

Yeme bozuklukları, sağlıkla ilişkili yaşam kalitesinde belirgin 
düşüşe neden olan ciddi hastalıklardır [16]. Duygusal yeme, kısıtlayıcı yeme ve dışsal yeme gibi yeme davranışlarının obezite ve yeme bozukları için risk faktörü olduğu daha önce yapılan çalışmalarda bildirilmiştir $[17,18]$. Duygusal yeme, stres, anksiyete, depresyon ve öfke gibi olumsuz duygularla baş edebilmek için gelişen fazla yeme davranışıdır. Özellikle stresin daha fazla yaşandığı gençlik döneminde duygusal yemenin daha fazla olduğu bildirilmiştir [19]. Dışsal yeme, özellikle besinin görünümü, kokusu gibi dışsal faktörlerin etkisine, açlık hissi gibi içsel faktörlerin etkisine göre daha hassas olan insanlarda görülmektedir. Özellikle obezojenik çevrenin dışsal yemeyi uyardığı bilinmektedir. Kısıtlayıcı yeme, paradoksal olarak, besin alımının azaltılması ile birlikte açlık sırasında aşırı besin tüketimi şeklinde ağırlık artışına neden olur [20].

$\mathrm{Bu}$ araştırma, yeme bozukluklarına yakalanma riski yüksek popülasyon olan üniversite öğrencilerinin yeme davranışlarını incelemek amacıyla 387 (\%53,3)'si kadın, 339 (\%46,7)'ü erkek 726 öğrenci ile yapılmıştır. Öğrencilerin bu yeme davranışları ile cinsiyet, VKI, yaşadıkları ortam, eğitim aldıkları bölüm arasındaki ilişkiler analiz edilmiştir.

Rusya'da yapılan bir çalışma kadınların her durumda erkeklerden daha yüksek puanlara sahip olduğunu göstermektedir. Rus örneğinde, erkeklerin sadece Kısıtlayıcı yeme skoru ile VKI ilişkili bulunmuştur. Böylece, Kısıtlayıcı ve Duygusal yeme erkek olmakla daha güçlü ilişkilendirilirken, Dışsal yeme erkekler ve kadınlar arasında eşit ilişkili olarak bulunmuştur. Bu nedenle, bu sonuçları hesaba katarak, öncelikle, genç kadınların kısıtlayıcı yeme ölçeklerinde daha yüksek puanlar aldıkları, kilo ile ilgili problemlerinin olmadığı ve yeme stratejilerinin gıda alımını kontrol etmek için dengeli bir yaklaşım içinde olmadığı, bazen dürtüsüz bir şekilde davranışlarını kısıtladıklarının varsayılabileceği belirtilmiştir. Bu etkinin yaşla birlikte azaldığı, buna göre bu gruptaki beslenme ve beden yaklaşımının yaşla birlikte değiştiği bildirilmiştir [21]. Bizim çalışmamız cinsiyete göre değerlendirildiğinde, duygusal yeme davranışının kadınlarda erkeklere göre istatistiksel olarak anlamlı farklılık yaratacak düzeyde fazla olduğu tespit edilmişken; kısıtlayıcı ve dışlayıcı yeme davranışında gruplar arasında anlamlı fark gözlenmedi. Üniversite popülasyonu zaten yaş dağılımı genç bir grup olduğu için yaşa için farka bakılmamıştır.

Yapılan bir çalışma duygusal yeme, kısıtlayıcı yeme alt boyutları ile antropometrik ölçümler arasında pozitif ilişki olduğunu gösterirken, dışsal yemenin antropometrik ölçümler üzerinde etkisinin anlamlı olmadığını belirtmektedir [22]. Türkiye'de yapılan başka bir çalışmada, üniversite öğrencilerinde kısıtlayıc yeme ile VKI arasında pozitif korelasyon bulunurken, dışsal yeme ve duygusal yeme ile VKI arasında herhangi bir ilişki bulunamamıştır [23]. Yapılan prospektif bir çalışmada ise kısıtlayıcı yemenin VKI'yi artırdığı gösterilmiştir [24]. İtalya'da yapılan bir çalışmada ise obez bireylerde dışsal yeme ve duygusal yeme puanları normal bireylerden daha yüksek bulunmuştur [15]. Yapılan çalışmalarda elde edilen sonuçların tutarlı olmaması, çalışma popülasyonun ırklarının, yaşadıkları çevrelerinin, beslenme alışkanlıklarının, yeme kültürlerinin, sosyodemografik ve ekonomik özelliklerinin farklı olmasından kaynaklanabilir.

Bizim çalışmamızda da VKI'ye göre yeme davranışları değerlendirildiğinde; duygusal yeme davranışı açısından anlamlı bir fark saptanmazken; dışsal ve kısıtlayıcı yeme davranışı açısından anlamlı farklılık saptandı.

Dışsal yeme skorunun, VKI arttıkça azaldığı ve Kısıtlayıcı yeme skorunun, VKI arttıkça artış gösterdiği bulunmuştur.

Literatürde katılımcıların eğitim gördükleri bölümlere ve yaşadıkları yere göre değerlendirilmelerine rastlanılmamıştır. Eğitim gördükleri bölümlere göre yeme davranışları değerlendirildiğinde; kısıtlayıcı yeme davranışı açısından anlamlı bir fark saptanmazken; duygusal ve dışlayıcı yeme davranışı açısından anlamlı farklılık saptandı.

Mühendislik fakültesi öğrencilerinde, fen-edebiyat fakültesi öğrencilerine göre daha az duygusal yeme gözlenirken, dışsal yeme skorunun daha fazla olduğu gözlenmiştir.

Katılımcıların yaşadıkları yere göre yeme davranışları değerlendirildiğinde; duygusal, kısıtlayıcı ve dışşal yeme davranışları açısından anlamlı farklılıklar saptandı.

Kısıtlayıcı yeme skoru, aileden ayrı evde tek yaşayanlarda daha düşük bulunurken, Dışsal yeme skoru, aile ile yaşayanlarda, arkadaşlarla ile evde yaşayanlara göre daha düşük bulunmuştur. Duygusal yeme skoru, özel yurtta yaşayanlarda daha yüksek bulunmuştur.

\section{Sonuç}

Bu çalışmada, genç popülasyonda, DEBQ'nun alt ölçeklerini uyguladığımız katılımcıların yeme davranış skorlarını, alanlarına, yaşadıkları yerlere, VKi'lerine ve cinsiyetlerine göre değerlendirdik ve yeme bozukluğu riski yüksek olan bu popülasyonda yapılan analiz sonucunda, , cinsiyet ve VKI'lerinin yeme davranışına etkisi olmasının yanında okudukları alanın ve yaşadıkları sosyal çevrenin de buna etkisinin olduğunu gösterdik.

\section{Çıkar çatışması/finansal destek beyanı}

Bu yazıdaki hiçbir yazarın herhangi bir çıkar çatışması yoktur. Yazının herhangi bir finansal desteği yoktur. 


\section{Kaynaklar}

1. World Health Organization (WHO). Erişim tarihi: 21 Şubat 2020. Availablefrom: http://www.who.int

2. Arlı $M$, Şanlıer $N$, Küçükkömürler $S$, Yaman $M$. Anne ve çocuk beslenmesi. Pegem Akademi 2017: 43-44.

3. Arslan M. Beslenme alışkanlıkları ve fiziksel aktivite düzeylerinin analizi: Marmara Üniversitesi öğretim üyeleri üzerine bir çalışma. Dicle Tıp Dergisi / Dicle Med J 2018; 45: 59-69.

4. Kaleli S, Kılıç N, Erdoğan M, Erdoğan N. Sakarya Üniversitesi Tıp Fakültesi öğrencilerinin beslenme alışkanlıkları. Online Türk Sağlık Bilimleri Dergisi 2017; 2: 12-8.

5. Chourdakis M, Tzellos T, Papazisis G, Toulis K, Kouvelas D. Eating habits, health attitudes and obesity indices among medical students in northern Greece. Appetite 2010; 55: 722-5

6. Goossens L, Braet C, Vlierberghe LV, Mels S. Loss of control over eating in overweight youngsters: the role of anxiety, depression and emotional eating. Eur Eat Disord Rev 2009; 17: 68-78.

7. Snoek HM, Engels RC, Janssens JM, van Strien T. Parental behaviour and adolescents' emotional eating. Appetite 2007; 49: 223-30.

8. Topham GL, Hubbs-Tait L, Rutledge JM et al. Parenting styles, parental response to childemotion, and familye motional responsiveness are related to childe motional eating. Appetite 2011; 56: 261-4.

9. Garibağaoğlu M, Budak N, Öner N, Sağlam Ö, Nişli K. Üç Farklı Üniversitede Eğitim Gören Kız Öğrencilerin Beslenme Durumları ve Vücut Ağırlıklarının Değerlendirmesi. Sağlık Bilimleri Dergisi 2006; 15: 173-80.

10. Yıldırım I, Yıldırım Y, Tortop Y, Poyraz A. Afyon Kocatepe Üniversitesi Beden Eğitimi ve Spor Yüksekokulu öğrencilerinin beslenme alışkanlıkları ve bunları etkileyen faktörler. Uluslararası İnsan Bilimleri Dergisi 2011; 8: 1375-91.

11. Ricca V, Castellini G, Fioravanti $G$ et al. Emotional eating in anorexia nervosa and bulimia nervosa. Compr Psy $\neg$ chiatry 2012; 53: 245-51.

12. van Strien T, Frijters JE, Roosen RG, Knuiman-Hijl WJ, Defares PB. Eating behavior, personality traits and body mass in women. Addict Behav 1985; 10: 333-43
13. Bozan N, Bas M, Asci FH. Psychometric properties of Turkish version of Dutch Eating Behaviour Questionnaire (DEBQ). A preliminary results. Appetite 2011; 56: 564-66

14. Porter KN, Johnson MA. Obesity is more strongly associated with in appropriate eating behaviors than with mental health in older adults receiving congregate meals. J Nutr Gerontol Geriatr 2011; 30: 403-15.

15. Allison DB, Kalinsky LB, Gorman BS. A comparative of the psychometric properties of three measures of dietary restraint Psychological Assessment 1992; 4: 391-8

16. Hoek HW. Review of the worldwide epidemiology of eating disorders. Curr Opin Psychiatry 2016; 29: 336-9.

17. van Strien $T$, Herman CP, Verheijden MW. Eating style, overeating and weight gain. A prospective 2-year follow-up study in a representative Dutch sample. Appetite 2012; 59:782-89.

18. Chaput JP, Leblanc C, Pérusse L, Després JP, Bouchard C, Tremblay A. Risk factors for adult overweight and obesity in the Quebec Family Study: have we been barking up the wrong tree? Obesity (Silver Spring) 2009; 17: 1964-70.

19. Wichianson JR, Bughi SA, Unger JB, Spruijt-Metz D, NguyenRodriguez ST. Perceived stress, coping and night-eating in college students. Stress Health 2009; 25: 235-40.

20. Snoek HM, Engels RC, van Strien T, Otten R. Emotional, external and restrained eating behaviour and $\mathrm{BMI}$ trajectories in adolescence. Appetite 2013; 67: 81-7.

21. Varlamov A, Vergeles K, Evgenia A. Adaptation and initial validation of DEBQ in a Russian sample. 2020, January 31. https://doi.org/10.31234/osf.io/np5ck.

22. Çil MA, Caferoğlu Z, Bilgiç P. Üniversite Öğrencilerinde Diyet Kalitesinin ve Yeme Davranışının Antropometrik Ölçümler ile İlişkisi. ACU Sağlık Bil Derg 2020; 11: 61-7.

23. Kayıran Z. The relationship between eating behaviours and daily energy intakes of students at the department of architecture at a university. phD Thesis, Yeditepe University, Health Sciences Institute, İstanbul; 2016.

24. van Strien $T$, Herman $C P$, Verheijden MW. Dietary restraint and body mass change. A 3-year follow up study in a representative Dutch sample. Appetite 2014; 76: 44-9. 